Review

\title{
Molecular Imaging of Stem Cells: Tracking Survival, Biodistribution, Tu- morigenicity, and Immunogenicity
}

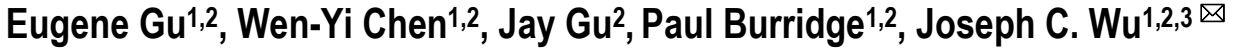 \\ 1. Department of Medicine, Division of Cardiology \\ 2. Department of Radiology, Molecular Imaging Program at Stanford (MIPS) \\ 3. Institute for Stem Cell Biology and Regenerative Medicine, Stanford University School of Medicine, Stanford, California \\ 94305, USA
}

Corresponding author: Joseph C. Wu, MD, PhD, 265 Campus Drive, Rm G1120B, Stanford CA 94305. Email: joewu@stanford.edu

(C) Ivyspring International Publisher. This is an open-access article distributed under the terms of the Creative Commons License (http://creativecommons.org/ licenses/by-nc-nd/3.0/). Reproduction is permitted for personal, noncommercial use, provided that the article is in whole, unmodified, and properly cited.

Received: 2011.10.19; Accepted: 2012.02.09; Published: 2012.04.01

\begin{abstract}
Being able to self-renew and differentiate into virtually all cell types, both human embryonic stem cells (hESCs) and induced pluripotent stem cells (iPSCs) have exciting therapeutic implications for myocardial infarction, neurodegenerative disease, diabetes, and other disorders involving irreversible cell loss. However, stem cell biology remains incompletely understood despite significant advances in the field. Inefficient stem cell differentiation, difficulty in verifying successful delivery to the target organ, and problems with engraftment all hamper the transition from laboratory animal studies to human clinical trials. Although traditional histopathological techniques have been the primary approach for ex vivo analysis of stem cell behavior, these postmortem examinations are unable to further elucidate the underlying mechanisms in real time and in vivo. Fortunately, the advent of molecular imaging has led to unprecedented progress in understanding the fundamental behavior of stem cells, including their survival, biodistribution, immunogenicity, and tumorigenicity in the targeted tissues of interest. This review summarizes various molecular imaging technologies and how they have advanced the current understanding of stem cell survival, biodistribution, immunogenicity, and tumorigenicity.
\end{abstract}

Key words: molecular imaging, stem cell therapy, survival, biodistribution, immunogenicity, tumorigenicity

\section{Introduction}

Human embryonic stem cells (hESCs) and induced pluripotent stem cells (iPSCs) possess great potential for regenerative medicine owing to their pluripotency and capacity for self-renewal. For instance, dopaminergic neurons derived from iPSCs [1] and ESCs [2] have been used to improve clinical symptoms of Parkinson's disease in the mouse model. Stem cells have also been differentiated into chrondrocytes to repair osteoarthritis [3], into cardiomyo- cytes to mitigate ischemic heart disease [4-6], and into insulin producing cells to potentially treat diabetes [7]. Transitioning from animal studies to humans has showcased the great promise of stem cell therapy, but has also exposed unanswered questions such as how effectively stem cells can migrate, engraft, and differentiate, and what risks tumorigenicity and immune rejection could pose to the patient. Over the last decade, advances in molecular imaging have allowed a 
deeper understanding of the in vivo behavior of stem cells and have proven to be indispensible in preclinical and clinical studies.

There are two main classes of molecular imaging techniques: direct stem cell labeling and reporter-gene imaging (Fig. 1). The former employs contrast agents such as magnetic particles, luminescent nanoparticles, or radionuclides to directly label the cell, whereas the latter genetically alters the cell to transcribe and translate a reporter protein. While direct labeling is both straightforward to implement and commonly used, the contrast signal is diluted with each cellular division and the technique cannot distinguish viable cells from dead cells [8]. Reporter-genes, on the other hand, are only expressed by live cells and the signal is propagated by daughter cells [9]. However, reporter gene imaging requires transfection of genetic material using plasmids, retroviral, or viral vectors, which raises the concern of insertional mutagenesis and may necessitate the use of apoptosis-inducing "suicide genes" before possible future use in the clinic $[10,11]$. This review will discuss current molecular imaging techniques and how they have advanced present understanding of stem cell survival, biodistribution, immunogenicity, and tumorigenicity.

B

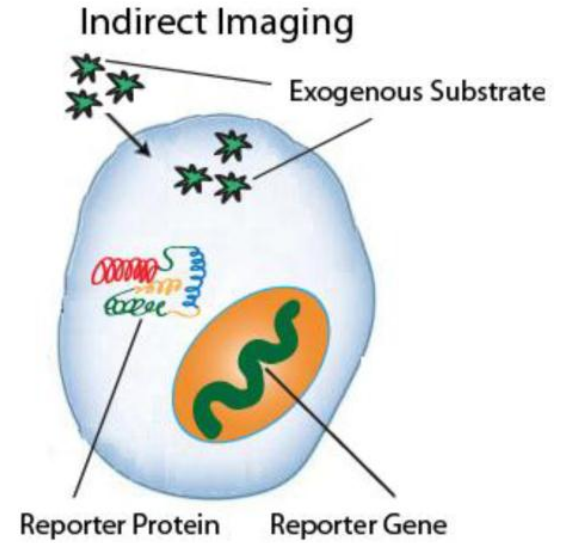

Figure I: a. Direct imaging involves the labeling of stem cells with MRI or PET tracers ex vivo. Common tracers include SPIOs for MRI and IIIIndium Oxine for PET imaging. b. Indirect imaging involves the expression of reporter genes that encode a reporter protein, which in turn metabolizes a substrate that produces a detectable signal.

\section{Direct Iron Particle Labeling}

As one of the first imaging modalities for monitoring pluripotent stem cells in vivo, magnetic resonance imaging (MRI) offers high spatial and temporal resolution to obtain detailed morphological and functional information. It requires the uptake of a contrast agent by the stem cell, the most common of which are superparamagnetic iron oxide (SPIO) nanoparticles. SPIOs can induce changes in T2 relaxivity at nanomolar concentrations [12], and many formulations are FDA-approved for clinical applications [13]. There are two main methods by which stem cells can be directly labeled by SPIOs. One method, magnetoporation, involves the coating of anionic SPIOs with cationic transfection agents such as protamine sulfate or poly-L-lysine [14]. Stem cells subsequently endocytose the resulting complex during incubation for around 24-48 hours [15]. Although many studies have shown that magnetoporation does not affect cell viability or function at low doses [15-17], there is evidence that high doses can inhibit mesenchymal stem cell (MSC) migration and colony formation ability [18]. Another study showed inhibition of chondrogenesis in MSCs after FDA-approved Feridex labeling [19]. The second method, magnetoelectroporation, uses low voltage pulses to induce endocytosis of SPIO particles. It works much more rapidly than magnetoporation and is likewise relatively innocuous to the cell at lower doses [20].

Several groups have shown the use of SPIOs for non-invasive MRI of neural stem cell migration, engraftment, and morphological differentiation [21, 22]. The contrast signals in these studies were detected for up to six weeks and the stem cells retained the ability to proliferate and differentiate. Other groups have shown that MRI can be used to track MSCs in cardiac repair after myocardial infarction [14, 23]. Here the signals could be detected long term for three to eight weeks. However, one disadvantage inherent to both SPIO labeling methods is their inability to distinguish viable cells from dead cells or from scavenging macrophages. This is due to the contrast material linger- 
ing in the transplanted cells even after the cells have died, or because the SPIO particles may be absorbed by macrophages responsible for removing dead cells [9]. Moreover, T2 contrast agents such as SPIOs induce hypointensities on a T1 weighted map, which can be misinterpreted as blood clots or hemhorrage in certain situations [24]. Fortunately, manganese based reagents may help overcome both limitations. For example, manganese chloride can only enter live cells through the voltage-gated calcium channel and has been used to assess the viability of both human ESCs and bone marrow stromal cells in vitro [25, 26]. Moreover, all manganese based reagents, including manganese oxide $(\mathrm{MnO})$ nanoparticles, induce $\mathrm{T} 1$ hyperintensities and therefore reduce clinical confusion [24]. MnO nanoparticles have been used to label and track MSCs in mice and to image gliblastomas in vivo $[27,28]$.

\section{Direct Radionuclide Imaging}

The advantages of radioscintigraphic techniques include their picomolar sensitivity, good tissue penetration, and translation to clinical applications [8]. In fact, radionuclide imaging is the sole direct labeling technique used thus far in human studies, involving both autologous bone marrow-derived stem cells [29] and peripheral hematopoietic stem cells [30-32]. There are two main techniques for radionuclide imaging: positron emission tomography (PET) and single photon emission computed tomography (SPECT). SPECT tracers directly emit a gamma ray in one direction, in contrast to PET tracers, which send two gamma rays in opposite directions and thus possess coincidence detection with a higher spatial resolution. However, SPECT is generally less expensive due to its longer-lived and more readily available radioisotopes.

The most widely used PET isotopes are fluorine-18 $\left.{ }^{18} \mathrm{~F}\right)$, which has a half-life of 110 minutes, and copper-64 $\left({ }^{64} \mathrm{Cu}\right)$, which has a much longer half-life of 12.7 hours [33]. ${ }^{18} \mathrm{~F}$ is incorporated into a radiolabeled glucose analog, 2-deoxy-2-18F-fluoro-D-glucose ( $\left.{ }^{18} \mathrm{~F}-\mathrm{FDG}\right)$, with the radioactive ${ }^{18} \mathrm{~F}$ substituted for the hydroxyl group at the $2^{\prime}$ position. Upon phosphorylation by hexokinase, ${ }^{18} \mathrm{~F}-\mathrm{FDG}$ remains in the intracellular space. ${ }^{18}$ F-FDG has been used to assess the migration and biodistribution of intracoronary injected bone marrow [29] and peripheral hematopoietic stem cells [30-32] in humans. ${ }^{18} \mathrm{~F}$ can also be incorporated into a modified thymidine analog, $3^{\prime}$-deoxy-3'-18 F-fluorothymidine $\left({ }^{18} \mathrm{~F}-\mathrm{FLT}\right)$, which is phosphorylated by thymidine kinase but not incorporated into DNA, thus sequestering ${ }^{18} \mathrm{~F}-\mathrm{FLT}$ within the cell. ${ }^{18} \mathrm{~F}-\mathrm{FLT}$ has been used to visualize neural stem cell mobilization in the mouse hippocampus
[34]. While ${ }^{18}$ F-FLT has been used to image tumor proliferation [35], there is evidence that this radiotracer is not useful for imaging teratomas resulting from embryonic stem cells [36].

With an increased half-life, ${ }^{64} \mathrm{Cu}$ can offer a longer duration of in vivo visualization of stem cell behavior. ${ }^{64} \mathrm{Cu}$ can be bound to an arginine-glycine-aspartic (RGD) tetramer conjugated with the macrocyclic chelator 1,4,7,10tetraazacyclododecane- $\mathrm{N}, \mathrm{N}^{\prime}, \mathrm{N}^{\prime \prime}, \mathrm{N}^{\prime \prime \prime}$-tetraacetic acid (DOTA) to form ${ }^{64} \mathrm{Cu}$-DOTA-RGD4. A recent study showed the ability of ${ }^{64} \mathrm{Cu}$-DOTA-RGD4 to target $\mathrm{a}_{\mathrm{v}} \beta_{3}$ integrin to noninvasively visualize teratoma formation of hESCs in vivo [36]. ${ }^{64} \mathrm{Cu}$ can also be bound to a lipophilic redox-active carrier molecule, pyruvaldehyde-bis( $N^{4}$-methylthiosemicarbazone) (PTSM). ${ }^{64} \mathrm{Cu}$-PTSM has been used to image hESCs differentiated towards renal lineages in fetal rhesus monkeys [37] and has been shown to lack adverse cellular effects [38].

The most widely used SPECT radionuclides are indium-111 (111In), with a half-life of 67 hours, and the metastable Technetium-99m ( $99 \mathrm{mTc})$, with a half-life of 6 hours. While ${ }^{111}$ In provides a longer time window for cell imaging, ${ }^{99 \mathrm{~m} T c}$ can be used in higher doses to improve short-term imaging resolution. Several groups have used ${ }^{111}$ In to image in vivo trafficking and biodistribution of MSCs around sites of myocardial injury in the canine $[39,40]$ and porcine animal models [41]. Human clinical studies have also used ${ }^{111}$ In-oxine [31, 42, 43] and 99mTc-Hexamethylpropleneamine oxine [44-46] to assess stem cell trafficking in acute and chronic myocardial infarction.

Although both PET and SPECT offer great sensitivity, there are several disadvantages to both techniques, including the leakage of radionuclides into non-target cells [47], limited time window for imaging due to half-life decay, lower spatial resolution as compared to MRI, and the emission of ionizing radiation that may impair stem cell proliferation and survival. However, in the case of MSCs, it has been shown that free radical scavenging and DNA repair mechanisms are particularly robust, allowing for higher radiotolerance [48].

\section{Optical Reporter Gene Imaging}

Capable of generating long-term signal contrast exclusively in live cells, optical reporter gene imaging is an extremely powerful tool for understanding stem cell biology. Bioluminescence imaging (BLI) involves the light-emitting oxidation of exogenously delivered substrate D-luciferin by the enzyme firefly luciferase (Fluc), which is encoded by the transgenically incorporated gene luc of the North American firefly Phon- 
tinus pyralis. Since animal tissues emit negligible visible light, the signal-to-background ratio and sensitivity of BLI are very high. Moreover, the signal is not only proportional to the total number of stem cells imaged, which allows for quantitative measurements, but persists so long as Fluc is expressed and D-luciferin is administered, thus facilitating longitudinal monitoring of cell survival. Given its low cost and simplicity, BLI has been used extensively in small animal studies, including the tracking of hematopoietic stem cell engraftment $[49,50]$ and the assessment of various stem cell types in the murine myocardial infarction model [51-54]. However, all luciferase emissions are in the visible spectrum, which is prone to scattering and absorption in tissue. Even firefly luciferase, with a comparatively long peak wavelength of $562 \mathrm{~nm}$, is limited to use in small animals due to a maximum penetration of $3 \mathrm{~cm}$ in tissue [55].

In contrast to BLI, fluorescence imaging (FLI) uses an external light source to excite a variety of fluorescent compounds, the most common of which is green fluorescent protein (GFP). Structurally, GFP is a beta barrel with a centrally located tripeptide sequence undergoing cyclization reactions in the presence of oxygen to serve as the chromophore [56]. When exposed to blue light at an excitation peak of $395 \mathrm{~nm}$, the chromophore emits green light at a longer peak wavelength of $509 \mathrm{~nm}$ due to Stokes shift [56]. One of the first studies to employ non-invasive FLI of homeostatic stem cells examined the skin stem cell niche in transgenic mice [57]. Imaging with GFP has also been used to study the growth and invasiveness of cancer cells within the microenvironment of hESC-derived teratomas [58] as well as gene expression in hESCs [59]. Like BLI, FLI is limited by its high scattering and absorbance in mammalian tissues. Although longer wavelength fluorescent proteins may improve tissue penetration depth, one study showed that Discosoma red fluorescent protein had a negative impact on hematopoietic stem cell survival compared to GFP for long-term imaging [60].

\section{Radionuclide Reporter Gene Imaging}

The best known and most widely used reporter gene for both PET and SPECT imaging is the herpes simplex virus type 1 thymidine kinase gene (HSV1-tk). Unlike mammalian thymidine kinase, herpes thymidine kinase can phosphorylate two main classes of exogenously administered reporter probes: pyrimidine analog derivatives such as 2'-fluoro-2'-deoxy- $\beta$-D-arabinofuranosyl-5-iodouracil (FIAU), and acycloguanosine derivatives such as 9-(4-fluoro-3-hydroxy-methyl-butyl)guanine (FHBG). When herpes thymidine kinase phosphorylates its reporter probe, not only is the probe retained within viable cells, but signal amplification also occurs when the enzyme reacts with multiple substrates [61].

To facilitate either PET or SPECT imaging, FIAU can be synthesized with the appropriate isotope such as positron emitting iodine-124 (124I) or gamma emitting iodine-125 (125I). SPECT imaging with ${ }^{125 I-F I A U ~}$ has been used to detect teratoma formation in mice transplanted with hESCs [61]. In terms of PET imaging, FHBG is most commonly used with ${ }^{18} \mathrm{~F}$ isotope. ${ }^{18} \mathrm{~F}-\mathrm{FHBG}$ has been used to assess tracking and survival of MSCs in porcine myocardium [62] as well as to assess migration of MSCs to tumor stroma [63].

Another reporter gene for PET and SPECT imaging is the sodium iodide symporter (NIS), a transmembrane protein responsible for the uptake of iodine in thyroid cells. When expressed in non-thyroid cells through transfection, NIS allows PET imaging with ${ }^{124}$ I and SPECT imaging with ${ }^{123}$ I or ${ }^{99 m}$ Tc. NIS has been used to image in vivo cardiac stem cell transplantation [64] as well as MSC migration to breast cancer tumor stroma, with possible therapeutic implications through the use of ${ }^{131}$ [ [65].

Advantages of radionuclide reporter genes include its high sensitivity and ability to detect only live cells, the possibility of using ganciclovir to commandeer HSV1-tk as a suicide gene to mitigate the risks of tumorigenicity [11], and the dual use of NIS as an imaging and therapeutic tool [65]. Disadvantages include leakage of radiotracers from labeled cells and non-specific uptake by normal tissues [66].

\section{MR Reporter Gene Imaging}

Of all reporter gene modalities, MRI offers the most detailed anatomic and spatial resolution in soft tissues. The first MRI reporter gene encoded a creatine kinase enzyme that generated phosphocreatine detectable by ${ }^{31} \mathrm{P}$ magnetic resonance spectroscopy (MRS) in the rat liver [67]. Since then, four main categories of MRI reporter genes have emerged. They involve increasing endogenous accumulation of iron [68-70], exploiting cell surface interactions [71, 72], harnessing enzymatic reactions $[67,73,74]$, or employing chemical exchange saturation transfer (CEST) $[75,76]$.

Iron's effect on $\mathrm{T}^{*}$ field inhomogeneity makes the manipulation of intracellular iron an effective contrast generation technique. Overexpression of ferritin, for example, causes a compensatory upregulation of transferrin receptors, which in turn increases intracellular iron levels. Ferritin reporter genes have been used to track porcine cardiac stem cells in the murine heart [69] and ESCs in transgenic mice [70]. Both studies showed no detrimental effects on stem 
cell differentiation or proliferation.

Manipulating cell surface interactions has also shown great potential. The high affinity between biotin and avidin is the strongest non-covalent interaction known to science with a dissociation constant of $10^{-15}$ [71]. A reporter gene encoding for a biotin acceptor peptide can be metabolically biotinylated by endogenous biotin ligase and expressed on the cell surface. When exposed to exogenously delivered contrast-labeled streptavidin, the cell can be visualized by MRI [71]. Reporter genes for cell surface antigen can also be used in conjunction with contrast-labeled antibody. One recent study employed SPIO-labeled antibody to assess ESC survival and teratoma formation in the murine heart [72].

Enzyme-based reporter genes include $\beta$-galactosidase, which cleaves galactose from specific contrast agents to expose the free coordination site of gadolinium, and human tyrosinase, which increases the production of metal-ion binding melanin. $\beta$-galactosidase has been used with substrate S-Gal ${ }^{\mathrm{TM}}$ for in vivo visualization of bone marrow cells in mice [73], and one study used human tyrosinase to image breast cancer cells [74].

Perhaps the most promising and versatile of all MRI reporter modalities is the chemical exchange saturation transfer (CEST) technique. Amide protons in polypeptides such as poly-L-lysine have a nuclear magnetic resonance frequency distinct from that of solvent water protons, which can be manipulated with a radiofrequency pulse (RF) to perturb the Bolzmann distribution of spins [75]. This perturbation is transferred through chemical exchange only to water protons that are in chemical equilibrium with the CEST reporter protein's exchangeable protons [75]. CEST has numerous advantages: its "switchable" nature in which contrast is detectable only when the radiofrequency pulse is applied; the innocuous biodegradable property of the reporter protein; and its capability to image multiple anatomic locations using different excitation frequencies when different contrast agents are used. While CEST has been used to image rat glioma cells in vivo, this technique has not been used in stem cell research to date [71].

\section{Monitoring Survival and Biodistribution}

Maintaining long-term survival and accurate homing of stem cells in animal models must first be accomplished before any meaningful clinical applications in humans can begin. Since direct imaging techniques are complicated by leakage of contrast and persistence of signal in non-viable cells $[8,40]$, sensitive reporter gene modalities are most appropriate for assessing survival, whereas direct imaging is more suitable for high resolution detection of cell location $[9,76]$. The first study to demonstrate reporter gene imaging of transplanted cells showed that BLI and ${ }^{18} \mathrm{~F}-\mathrm{FHBG}$ correlated with the gold standard ex vivo histopathological analysis and were feasible for measuring cell survival [77]. However, subsequent studies have shown that very few cells home in on and survive in the target organ long-term. One study showed that eight weeks after transplantation, less than $0.5 \%$ of transplanted cardiac stem cells were still alive in a rat model of myocardial infarction [52]. Another study used BLI to compare the survival of transplanted bone marrow mononuclear cells (MNs), MSCs, skeletal myoblasts, and fibroblasts in the mouse myocardium and found that although MNs transiently displayed higher survival rates than other cell types, the effect was short-lived with only $0.4 \%$ of MNs surviving after 6 weeks [51]. Furthermore, in vivo analysis of biodistribution showed that a significant number of MNs injected into the heart actually migrated to the femur, liver, and spleen (Fig. 2) [51].

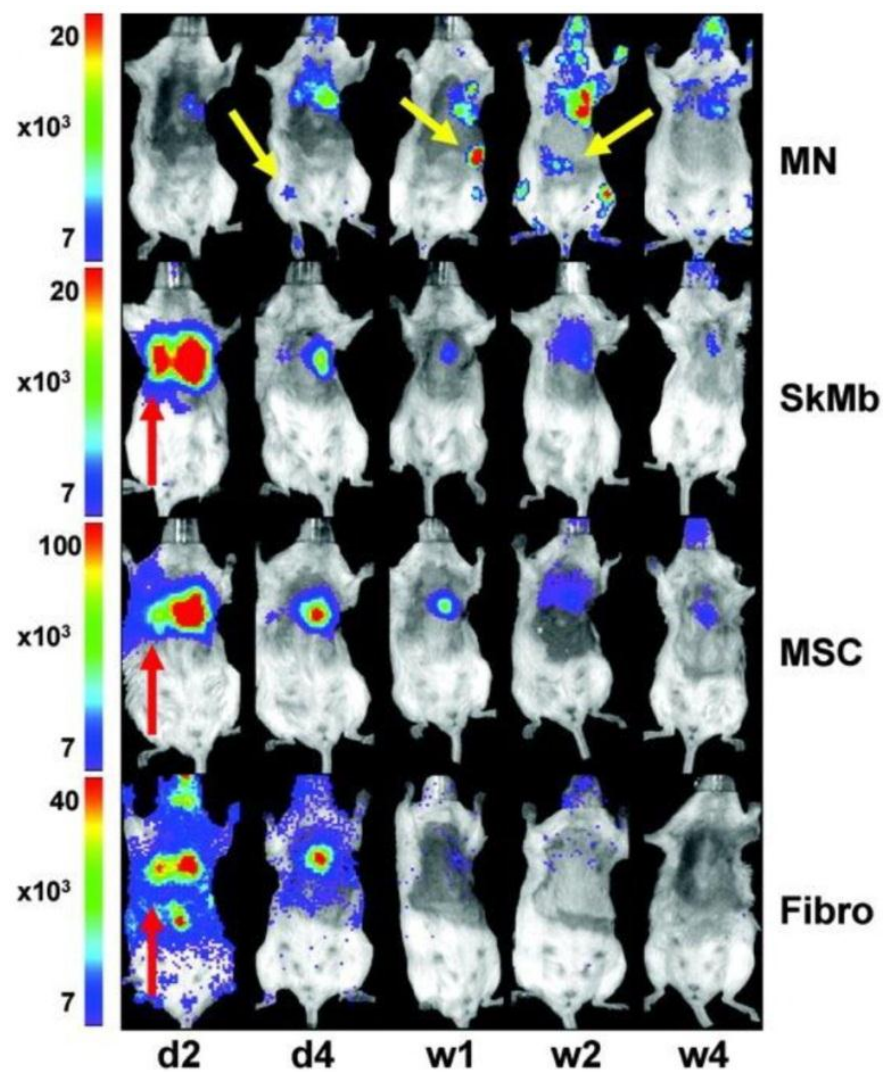

Figure 2: In vivo bioluminescence imaging (BLI) in the murine myocardial infarction model showing transplanted mononuclear cells (MNs) homing in on the heart as well as the femur, spleen, and liver (yellow arrows). Skeletal myoblasts (SkMb), mesenchymal stem cells (MSCs), and fibroblasts (fibro) migrate not only to the heart but also to the lungs (red arrows). Reprinted with permission from [47]. 
An additional biodistribution study in humans using PET imaging with ${ }^{18} \mathrm{~F}-\mathrm{FDG}$ showed that only $1.5 \%$ of intracoronary infused peripheral blood mononuclear cells accumulated at the myocardium [30].

Multiple studies have investigated methods of improving stem cell survival and biodistribution, including the overexpression of certain genes. In vitro studies have shown that overexpression of BCL2 confers an anti-apoptotic survival benefit to hESCs in conditions of stress, such as serum- and feeder-free conditions or single-cell dissociation [78]. An in vivo study using BLI showed that overexpression of BCL2 confers a significant survival advantage to cardiomyoblasts, but only within the first four weeks of transplantation [79]. This may be primarily due to anti-apoptotic effects during the early stresses of transplantation. Another study using fluorescence reporter imaging with GFP showed that overexpression of CXCR4 in MSCs led to enhanced homing and engraftment in the ischemic myocardium [80]. The cells promoted myoangiogenesis and improved early signs of left ventricular remodeling.

MicroRNAs (miRNAs) can also be used to suppress downstream pro-apoptotic genes. One study using BLI showed that a cocktail of three miRNAs (miR-21, miR-24, and miR-221) significantly improved the survival and engraftment of cardiac progenitor cells in a murine myocardial infarction model [81]. Here the BLI signal could be detected for up to 28 days and was significantly higher in the cells treated with the miRNA cocktail. One proposed mechanism for this effect is the downstream suppression of the proapoptotic Bim protein.

A significant drawback to genetic overexpression and or even suppression techniques is the potential for oncogenic transformation. Hypoxic preconditioning (HP) is therefore an attractive alternative that encourages endogenous production of prosurvival factors such as HIF-1a and HIF-2a [82]. One study showed that BLI could be used to assess short-term survival of HP-enhanced mesenchymal stromal cells [83]. Although the preconditioned cells demonstrated increased survival under hypoxic challenge compared to controls, no long-term tracking was conducted. Future investigations into physiologic preconditioning, using in vivo molecular imaging with longer follow-up times, may help further elucidate the underlying mechanisms of stem cell survival and homing. In addition, multimodality imaging combining high sensitivity PET with high resolution MRI may allow not only simultaneous monitoring of survival and biodistribution, but also demonstrate clinical applicability.

\section{Monitoring Tumorigenicity}

Pluripotent stem cells share many properties in common with cancer cells, including self-renewal, rapid proliferation, lack of contact inhibition, and high telomerase activity [84, 85]. Furthermore, cellular manipulations, such as the reprogramming of somatic cells into iPSCs, transfection of reporter genes, and overexpression of survival genes, can have unintended tumorigenic side effects. Teratoma formation is another concern, along with its potential to degenerate into malignant teratocarcinomas [84]. Given these risks, understanding stem cell tumorigenicity is of paramount importance for future clinical applications.

One study using a double fusion reporter containing Fluc and GFP showed that teratoma formation is dependent upon cell number. Assessed over a period of eight weeks, a minimum of $1 \times 10^{5}$ intramyocardially injected hESCs were required to form teratomas in mice [86]. Furthermore, a lower threshold of $1 \times 10^{4}$ cells following hindlimb injection was required to form teratomas, providing insight into niche-dependency (Fig. 3) [82]. Since angiogenesis is known to play a major role in tumor growth and development, it is important to investigate not only the tumor itself but also its supporting stroma. One study used NIS reporter imaging to show that MSCs actively home in on growing tumors, where they differentiate into vasculature and supporting structures [65]. The upregulation of $\alpha_{v} \beta_{3}$ integrin is also known to play a role in tumor angiogenesis [87]. One study used direct PET imaging with ${ }^{64} \mathrm{Cu}$-DOTA-RGD4 to target $\alpha_{v} \beta_{3}$ integrin, which successfully visualized in vivo hESC teratoma formation in the mouse model [36]. These findings show that integrins play a major role in teratoma formation and angiogenesis. Moreover, PET imaging may have promising clinical applicability for monitoring tumorigenicity in humans because BLI lacks the ability to penetrate deep tissues.

Due to the risks of teratoma formation, having a reporter gene that serves as both an imaging modality as well as a fail-safe suicide switch would be highly desirable. One study used HSV1-tk PET reporter imaging to selectively destroy emerging teratomas with the administration of ganciclovir [11]. Future directions for mitigating the risks of tumorigenicity include not only the use of reporter-suicide genes, but also vector- and transgene-free reprogramming of somatic cells into iPSCs [88, 89] and long-term multimodality imaging capable of observing both emerging tumor cells and their supporting stroma. 


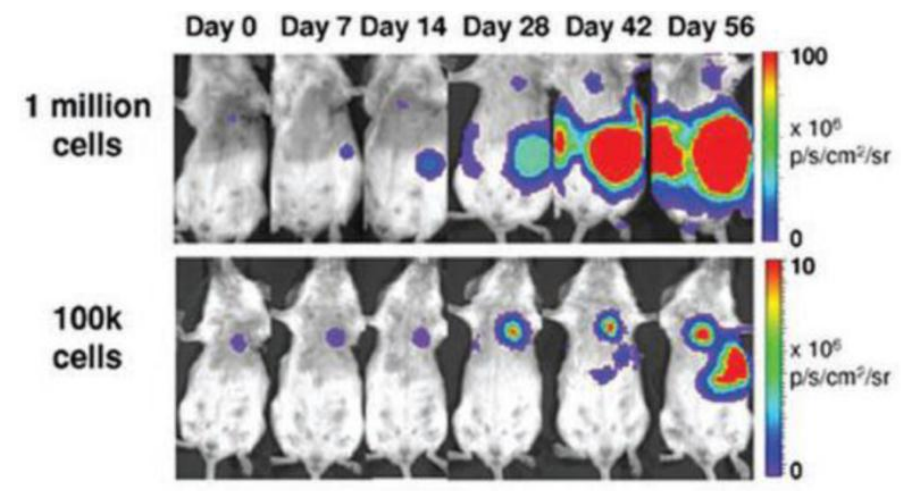

Day 0 Day 7 Day 14 Day 28 Day 42 Day 56 Day 365

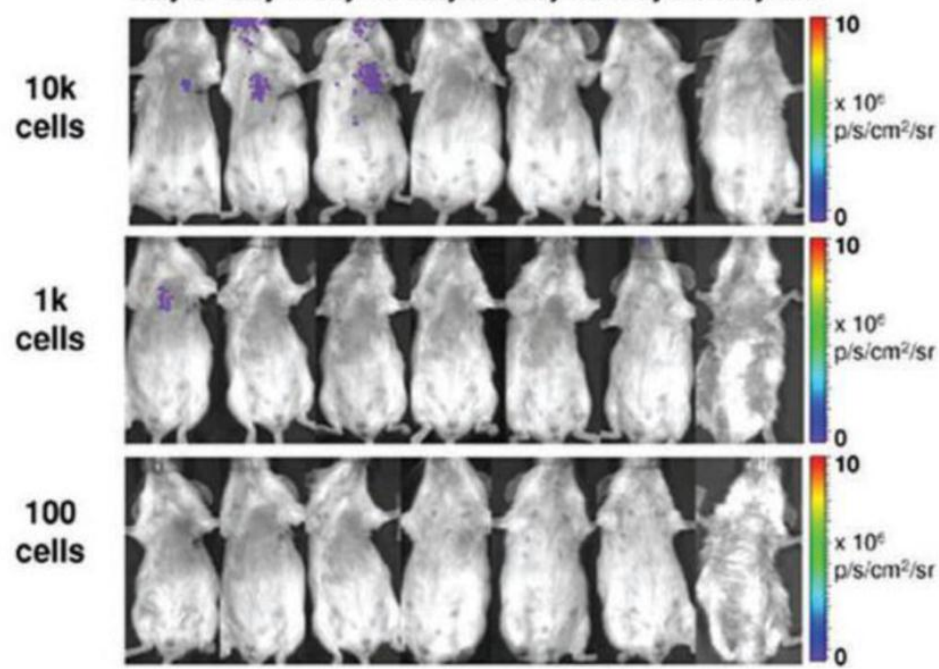

Figure 3: Teratoma formation is dependent upon cell number. BLI reveals that a minimum of I $\times 10^{5}$ human ESCs injected intramyocardially are needed to form teratomas in mice. Reprinted with permission from [82].

\section{Monitoring Immunogenicity}

Due to limited MHC class I expression and lack of MHC Class II expression, ESCs were assumed to be "immune privileged" until they were shown to cause immune rejection in the mouse model [90]. Although the immune response is lower against ESCs than allogeneic adult cells, it has been shown that even low levels of MHC class I expression can lead to a cytotoxic T-cell response [91]. This is exacerbated during the process of differentiation and teratoma formation, which causes an upregulation of MHC class I molecules [92]. Not only are ESCs immunogenic, more recent evidence suggests that even iPSCs can have abnormal gene expression leading to a T-cell mediated immune response in syngeneic mice [93]. Therefore, the immunogenicity of all stem cell derived therapeutic cells should be rigorously investigated in preclinical studies. In small animals, BLI has not only been used to confirm the fact that stem cell rejection occurs in immunocompetent recipients, but has also provided insight into therapeutic strategies to prevent rejection. One study used BLI to show that transplanted xenogeneic human ESCs in immunocompetent mice survived only 7 to 10 days after primary injection, and only 3 days after repeat transplantation [94]. Both cell-mediated and humoral responses were shown to be involved, and addition of immunosuppressive therapy with sirolimus and tacrolimus lengthened survival to 28 days [94]. Another study used BLI to demonstrate that short-term immunosuppression with leukocyte costimulatory blockade agents allowed long-term engraftment of xenogeneic human ESCs and iPSCs (Fig. 4) [95]. 


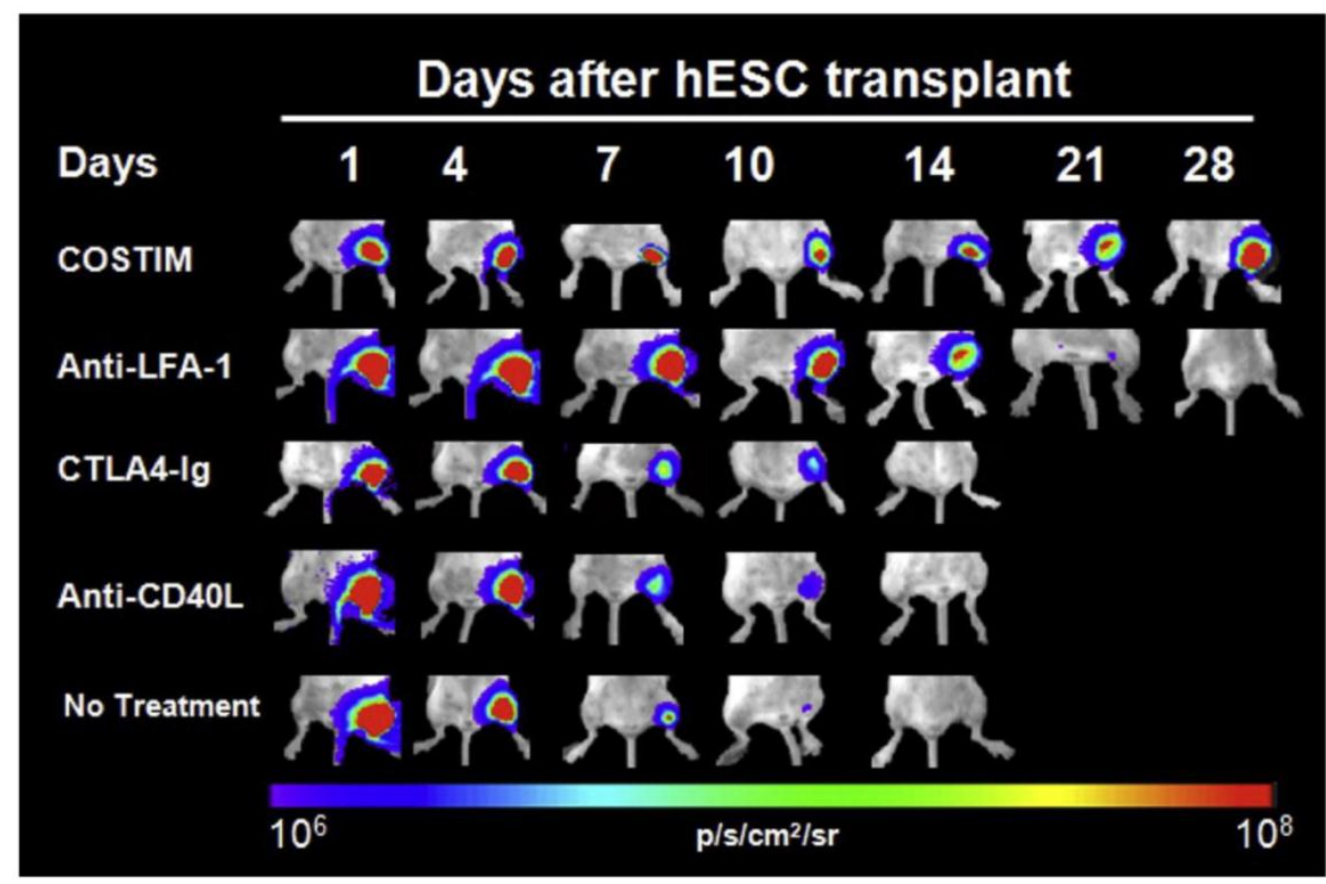

Figure 4: Longitudinal bioluminescence images of xenogeneic human ESC-transplanted mice that received no treatment, monotherapy, or a combination of all three costimulatory blockade agents (COSTIM). Reprinted with permission from [9I].

\section{Conclusions}

Before clinical applications in humans, potential therapeutic stem cell treatments must undergo extensive scrutiny. Although a great deal of information is already known about the survival, biodistribution, tumorigenicity, and immunogenicity of pluripotent stem cells, significant gaps in knowledge remain. Molecular imaging will continue to play a pivotal role in answering crucial questions about clinical applications as well as in helping us understand the underlying mechanisms of stem cell biology. Currently, the effectiveness of stem cell therapy in terms of both cell survival and proper engraftment in animal models is far from ideal. With less than $1 \%$ of cells surviving or correctly localizing to target tissues, significant improvement is needed before meeting clinical standards. In that regard, hypoxic preconditioning, gene therapy, pro-survival biopolymers, and tissue engineering represent promising techniques to improve cell survival. However, more in vivo molecular imaging studies must be conducted to confirm long-term survival of these cells. The safety of stem cell therapy in terms of tumorigenicity and immune rejection must also be thoroughly examined. To that end, molecular imaging studies capable of evaluating the risk of cancer formation long-term or assessing methods of immune suppression for viable engraftment are highly valuable.

\section{Acknowledgement}

Due to space limitations, we are unable to include all of the important papers relevant to induced pluripotent stem cell derivation and application; we apologize to those investigators whose works we omitted here. This work was supported by the HHMI Medical Student Fellowship (EG); NIH HL099117 and NIH EB009689 (JCW).

\section{Competing Interests}

The authors have declared that no competing interest exists.

\section{References}

1. Wernig M, Zhao JP, Pruszak J, Hedlund E, Fu D, Soldner F, et al. Neurons derived from reprogrammed fibroblasts functionally integrate into the fetal brain and improve symptoms of rats with Parkinson's disease. Proc Natl Acad Sci U S A. 2008; 105: 5856-61.

2. Yang D, Zhang ZJ, Oldenburg M, Ayala M, Zhang SC. Human embryonic stem cell-derived dopaminergic neurons reverse functional deficit in parkinsonian rats. Stem Cells. 2008; 26: $55-63$.

3. Djouad F, Bouffi C, Ghannam S, Noel D, Jorgensen C. Mesenchymal stem cells: innovative therapeutic tools for rheumatic diseases. Nat Rev Rheumatol. 2009; 5: 392-9.

4. Zhang J, Wilson GF, Soerens AG, Koonce CH, Yu J, Palecek SP, et al. Functional cardiomyocytes derived from human induced pluripotent stem cells. Circ Res. 2009; 104: e30-41. 
5. Cao F, Wagner RA, Wilson KD, Xie X, Fu JD, Drukker M, et al. Transcriptional and functional profiling of human embryonic stem cell-derived cardiomyocytes. PLoS One. 2008; 3: e3474.

6. Nelson TJ, Martinez-Fernandez A, Yamada S, Perez-Terzic C, Ikeda Y, Terzic A. Repair of acute myocardial infarction by human stemness factors induced pluripotent stem cells. Circulation. 2009; 120: 408-16.

7. Kroon E, Martinson LA, Kadoya K, Bang AG, Kelly OG, Eliazer $\mathrm{S}$, et al. Pancreatic endoderm derived from human embryonic stem cells generates glucose-responsive insulin-secreting cells in vivo. Nat Biotechnol. 2008; 26: 443-52.

8. Welling MM, Duijvestein M, Signore A, van der Weerd L. In vivo biodistribution of stem cells using molecular nuclear medicine imaging. J Cell Physiol. 2011; 226: 1444-52.

9. Li Z, Suzuki Y, Huang M, Cao F, Xie X, Connolly AJ, et al. Comparison of reporter gene and iron particle labeling for tracking fate of human embryonic stem cells and differentiated endothelial cells in living subjects. Stem Cells. 2008; 26: 864-73.

10. Niculescu-Duvaz I, Springer CJ. Introduction to the background, principles, and state of the art in suicide gene therapy. Mol Biotechnol. 2005; 30: 71-88.

11. Cao F, Drukker M, Lin S, Sheikh AY, Xie X, Li Z, et al. Molecular imaging of embryonic stem cell misbehavior and suicide gene ablation. Cloning Stem Cells. 2007; 9: 107-17.

12. Sykova E, Jendelova P, Herynek V. Magnetic resonance imaging of stem cell migration. Methods Mol Biol. 2011; 750: 79-90.

13. Frank JA, Miller BR, Arbab AS, Zywicke HA, Jordan EK, Lewis $\mathrm{BK}$, et al. Clinically applicable labeling of mammalian and stem cells by combining superparamagnetic iron oxides and transfection agents. Radiology. 2003; 228: 480-7.

14. Kraitchman DL, Heldman AW, Atalar E, Amado LC, Martin BJ, Pittenger MF, et al. In vivo magnetic resonance imaging of mesenchymal stem cells in myocardial infarction. Circulation. 2003; 107: 2290-3

15. So PW, Kalber T, Hunt D, Farquharson M, Al-Ebraheem A, Parkes HG, et al. Efficient and rapid labeling of transplanted cell populations with superparamagnetic iron oxide nanoparticles using cell surface chemical biotinylation for in vivo monitoring by MRI. Cell Transplant. 2010; 19: 419-29.

16. Bulte JW, Arbab AS, Douglas T, Frank JA. Preparation of magnetically labeled cells for cell tracking by magnetic resonance imaging. Methods Enzymol. 2004; 386: 275-99.

17. Bulte JW, Kraitchman DL. Iron oxide MR contrast agents for molecular and cellular imaging. NMR Biomed. 2004; 17: 484-99.

18. Schafer R, Kehlbach R, Muller M, Bantleon R, Kluba T, Ayturan $\mathrm{M}$, et al. Labeling of human mesenchymal stromal cells with superparamagnetic iron oxide leads to a decrease in migration capacity and colony formation ability. Cytotherapy. 2009; 11: 68-78.

19. Kostura L, Kraitchman DL, Mackay AM, Pittenger MF, Bulte JW. Feridex labeling of mesenchymal stem cells inhibits chondrogenesis but not adipogenesis or osteogenesis. NMR Biomed. 2004; 17: 513-7.

20. Walczak P, Kedziorek DA, Gilad AA, Lin S, Bulte JW. Instant MR labeling of stem cells using magnetoelectroporation. Magn Reson Med. 2005; 54: 769-74.

21. Bulte JW, Douglas T, Witwer B, Zhang SC, Strable E, Lewis BK, et al. Magnetodendrimers allow endosomal magnetic labeling and in vivo tracking of stem cells. Nat Biotechnol. 2001; 19: 1141-7.

22. Hoehn M, Kustermann E, Blunk J, Wiedermann D, Trapp T, Wecker $\mathrm{S}$, et al. Monitoring of implanted stem cell migration in vivo: a highly resolved in vivo magnetic resonance imaging investigation of experimental stroke in rat. Proc Natl Acad Sci U S A. 2002; 99: 16267-72.
23. Amado LC, Saliaris AP, Schuleri KH, St John M, Xie JS, Cattaneo $\mathrm{S}$, et al. Cardiac repair with intramyocardial injection of allogeneic mesenchymal stem cells after myocardial infarction. Proc Natl Acad Sci U S A. 2005; 102: 11474-9.

24. Zhen Z, Xie J. Development of manganese-based nanoparticles as contrast probes for magnetic resonance imaging. Theranostics. 2012; 2: 45-54.

25. Yamada M, Gurney PT, Chung J, Kundu P, Drukker M, Smith AK, et al. Manganese-guided cellular MRI of human embryonic stem cell and human bone marrow stromal cell viability. Magn Reson Med. 2009; 62: 1047-54.

26. Koretsky AP, Silva AC. Manganese-enhanced magnetic resonance imaging (MEMRI). NMR Biomed. 2004; 17: 527-31.

27. Huang J, Xie J, Chen K, Bu L, Lee S, Cheng Z, et al. HSA coated $\mathrm{MnO}$ nanoparticles with prominent MRI contrast for tumor imaging. Chem Commun (Camb). 2010; 46: 6684-6.

28. Kim T, Momin E, Choi J, Yuan K, Zaidi H, Kim J, et al. Mesoporous silica-coated hollow manganese oxide nanoparticles as positive $\mathrm{T} 1$ contrast agents for labeling and MRI tracking of adipose-derived mesenchymal stem cells. J Am Chem Soc. 2011; 133: 2955-61.

29. Hofmann M, Wollert KC, Meyer GP, Menke A, Arseniev L, Hertenstein $\mathrm{B}$, et al. Monitoring of bone marrow cell homing into the infarcted human myocardium. Circulation. 2005; 111: 2198-202.

30. Kang WJ, Kang HJ, Kim HS, Chung JK, Lee MC, Lee DS. Tissue distribution of 18F-FDG-labeled peripheral hematopoietic stem cells after intracoronary administration in patients with myocardial infarction. J Nucl Med. 2006; 47: 1295-301.

31. Schachinger V, Aicher A, Dobert N, Rover R, Diener J, Fichtlscherer $\mathrm{S}$, et al. Pilot trial on determinants of progenitor cell recruitment to the infarcted human myocardium. Circulation. 2008; 118: 1425-32.

32. Dedobbeleer $C$, Blocklet $D$, Toungouz $M$, Lambermont $M$, Unger P, Degaute JP, et al. Myocardial homing and coronary endothelial function after autologous blood CD34+ progenitor cells intracoronary injection in the chronic phase of myocardial infarction. J Cardiovasc Pharmacol. 2009; 53: 480-5.

33. Adonai N, Nguyen KN, Walsh J, Iyer M, Toyokuni T, Phelps $\mathrm{ME}$, et al. Ex vivo cell labeling with 64Cu-pyruvaldehyde-bis(N4-methylthiosemicarbazone) for imaging cell trafficking in mice with positron-emission tomography. Proc Natl Acad Sci U S A. 2002; 99: 3030-5.

34. Rueger MA, Backes H, Walberer M, Neumaier B, Ullrich R, Simard ML, et al. Noninvasive imaging of endogenous neural stem cell mobilization in vivo using positron emission tomography. J Neurosci. 2010; 30: 6454-60.

35. Shields AF, Grierson JR, Dohmen BM, Machulla HJ, Stayanoff JC, Lawhorn-Crews JM, et al. Imaging proliferation in vivo with [F-18]FLT and positron emission tomography. Nat Med. 1998; 4: 1334-6.

36. Cao F, Li Z, Lee A, Liu Z, Chen $\mathrm{K}$, Wang $\mathrm{H}$, et al. Noninvasive de novo imaging of human embryonic stem cell-derived teratoma formation. Cancer Res. 2009; 69: 2709-13.

37. Tarantal AF, Lee CC, Batchelder CA, Christensen JE, Prater D, Cherry SR. Radiolabeling and In Vivo Imaging of Transplanted Renal Lineages Differentiated from Human Embryonic Stem Cells in Fetal Rhesus Monkeys. Mol Imaging Biol. 2012 Apr;14(2):197-204.

38. Huang J, Lee CC, Sutcliffe JL, Cherry SR, Tarantal AF. Radiolabeling rhesus monkey CD34+ hematopoietic and mesenchymal stem cells with 64Cu-pyruvaldehyde-bis(N4-methylthiosemicarbazone) for microPET imaging. Mol Imaging. 2008; 7: 1-11.

39. Kraitchman DL, Tatsumi M, Gilson WD, Ishimori T, Kedziorek $\mathrm{D}$, Walczak $\mathrm{P}$, et al. Dynamic imaging of allogeneic 
mesenchymal stem cells trafficking to myocardial infarction. Circulation. 2005; 112: 1451-61.

40. Blackwood KJ, Lewden B, Wells RG, Sykes J, Stodilka RZ, Wisenberg G, et al. In vivo SPECT quantification of transplanted cell survival after engraftment using (111)In-tropolone in infarcted canine myocardium. J Nucl Med. 2009; 50: 927-35.

41. Lyngbaek S, Ripa RS, Haack-Sorensen M, Cortsen A, Kragh L, Andersen $\mathrm{CB}$, et al. Serial in vivo imaging of the porcine heart after percutaneous, intramyocardially injected 111In-labeled human mesenchymal stromal cells. Int J Cardiovasc Imaging. 2010; 26: 273-84.

42. Kurpisz M, Czepczynski R, Grygielska B, Majewski M, Fiszer $\mathrm{D}$, Jerzykowska $\mathrm{O}$, et al. Bone marrow stem cell imaging after intracoronary administration. Int J Cardiol. 2007; 121: 194-5.

43. Caveliers V, De Keulenaer G, Everaert H, Van Riet I, Van Camp $\mathrm{G}$, Verheye S, et al. In vivo visualization of 111In labeled CD133+ peripheral blood stem cells after intracoronary administration in patients with chronic ischemic heart disease. Q J Nucl Med Mol Imaging. 2007; 51: 61-6.

44. Mesquita CT, Correa PL, Felix RC, Azevedo JC, Alves S, Oliveira CC, et al. Autologous bone marrow mononuclear cells labeled with Tc-99m hexamethylpropylene amine oxime scintigraphy after intracoronary stem cell therapy in acute myocardial infarction. J Nucl Cardiol. 2005; 12: 610-2.

45. Penicka M, Lang O, Widimsky P, Kobylka P, Kozak T, Vanek T, et al. One-day kinetics of myocardial engraftment after intracoronary injection of bone marrow mononuclear cells in patients with acute and chronic myocardial infarction. Heart. 2007; 93: 837-41.

46. Goussetis E, Manginas A, Koutelou M, Peristeri I, Theodosaki $\mathrm{M}$, Kollaros $\mathrm{N}$, et al. Intracoronary infusion of CD133+ and CD133-CD34+ selected autologous bone marrow progenitor cells in patients with chronic ischemic cardiomyopathy: cell isolation, adherence to the infarcted area, and body distribution. Stem Cells. 2006; 24: 2279-83.

47. Stojanov K, de Vries EF, Hoekstra D, van Waarde A, Dierckx RA, Zuhorn IS. [(18)F]FDG Labeling of Neural Stem Cells for In Vivo Cell Tracking with Positron Emission Tomography: Inhibition of Tracer Release by Phloretin. Mol Imaging. 2011; epub.

48. Chen MF, Lin CT, Chen WC, Yang CT, Chen CC, Liao SK, et al. The sensitivity of human mesenchymal stem cells to ionizing radiation. Int J Radiat Oncol Biol Phys. 2006; 66: 244-53.

49. Cao YA, Wagers AJ, Beilhack A, Dusich J, Bachmann MH, Negrin RS, et al. Shifting foci of hematopoiesis during reconstitution from single stem cells. Proc Natl Acad Sci U S A. 2004; 101: 221-6.

50. Wang X, Rosol M, Ge S, Peterson D, McNamara G, Pollack H, et al. Dynamic tracking of human hematopoietic stem cell engraftment using in vivo bioluminescence imaging. Blood. 2003; 102: 3478-82.

51. van der Bogt KE, Sheikh AY, Schrepfer S, Hoyt G, Cao F, Ransohoff $\mathrm{KJ}$, et al. Comparison of different adult stem cell types for treatment of myocardial ischemia. Circulation. 2008; 118: S121-9.

52. Li Z, Lee A, Huang M, Chun $\mathrm{H}$, Chung J, Chu P, et al. Imaging survival and function of transplanted cardiac resident stem cells. J Am Coll Cardiol. 2009; 53: 1229-40.

53. Sheikh AY, Lin SA, Cao F, Cao Y, van der Bogt KE, Chu P, et al. Molecular imaging of bone marrow mononuclear cell homing and engraftment in ischemic myocardium. Stem Cells. 2007; 25: 2677-84.

54. Swijnenburg RJ, Govaert JA, van der Bogt KE, Pearl JI, Huang $\mathrm{M}$, Stein $\mathrm{W}$, et al. Timing of bone marrow cell delivery has minimal effects on cell viability and cardiac recovery after myocardial infarction. Circ Cardiovasc Imaging. 2010; 3: 77-85.
55. Sutton EJ, Henning TD, Pichler BJ, Bremer C, Daldrup-Link HE. Cell tracking with optical imaging. Eur Radiol. 2008; 18: 2021-32.

56. Yang F, Moss LG, Phillips GN, Jr. The molecular structure of green fluorescent protein. Nat Biotechnol. 1996; 14: 1246-51.

57. Tumbar T, Guasch G, Greco V, Blanpain C, Lowry WE, Rendl $\mathrm{M}$, et al. Defining the epithelial stem cell niche in skin. Science. 2004; 303: 359-63.

58. Tzukerman M, Rosenberg T, Ravel Y, Reiter I, Coleman R, Skorecki K. An experimental platform for studying growth and invasiveness of tumor cells within teratomas derived from human embryonic stem cells. Proc Natl Acad Sci U S A. 2003; 100: 13507-12.

59. Vallier L, Rugg-Gunn PJ, Bouhon IA, Andersson FK, Sadler AJ, Pedersen RA. Enhancing and diminishing gene function in human embryonic stem cells. Stem Cells. 2004; 22: 2-11.

60. Tao W, Evans BG, Yao J, Cooper S, Cornetta K, Ballas CB, et al. Enhanced green fluorescent protein is a nearly ideal long-term expression tracer for hematopoietic stem cells, whereas DsRed-express fluorescent protein is not. Stem Cells. 2007; 25: 670-8.

61. Pomper MG, Hammond H, Yu X, Ye Z, Foss CA, Lin DD, et al. Serial imaging of human embryonic stem-cell engraftment and teratoma formation in live mouse models. Cell Res. 2009; 19: 370-9.

62. Gyongyosi M, Blanco J, Marian T, Tron L, Petnehazy O, Petrasi $\mathrm{Z}$, et al. Serial noninvasive in vivo positron emission tomographic tracking of percutaneously intramyocardially injected autologous porcine mesenchymal stem cells modified for transgene reporter gene expression. Circ Cardiovasc Imaging. 2008; 1: 94-103.

63. Hung SC, Deng WP, Yang WK, Liu RS, Lee CC, Su TC, et al. Mesenchymal stem cell targeting of microscopic tumors and tumor stroma development monitored by noninvasive in vivo positron emission tomography imaging. Clin Cancer Res. 2005; 11: 7749-56

64. Terrovitis J, Kwok KF, Lautamaki R, Engles JM, Barth AS, Kizana E, et al. Ectopic expression of the sodium-iodide symporter enables imaging of transplanted cardiac stem cells in vivo by single-photon emission computed tomography or positron emission tomography. I Am Coll Cardiol. 2008; 52: 1652-60.

65. Dwyer RM, Ryan J, Havelin RJ, Morris JC, Miller BW, Liu Z, et al. Mesenchymal Stem Cell-mediated delivery of the sodium iodide symporter supports radionuclide imaging and treatment of breast cancer. Stem Cells. 2011; 29: 1149-57.

66. Jiang $\mathrm{H}$, Cheng $\mathrm{Z}$, Tian $\mathrm{M}$, Zhang $\mathrm{H}$. In vivo imaging of embryonic stem cell therapy. Eur J Nucl Med Mol Imaging. 2011; 38: 774-84.

67. Koretsky AP, Brosnan MJ, Chen LH, Chen JD, Van Dyke T. NMR detection of creatine kinase expressed in liver of transgenic mice: determination of free ADP levels. Proc Natl Acad Sci U S A. 1990; 87: 3112-6.

68. Genove G, DeMarco U, Xu H, Goins WF, Ahrens ET. A new transgene reporter for in vivo magnetic resonance imaging. Nat Med. 2005; 11: 450-4.

69. Campan M, Lionetti V, Aquaro GD, Forini F, Matteucci M, Vannucci $\mathrm{L}$, et al. Ferritin as a reporter gene for in vivo tracking of stem cells by 1.5-T cardiac MRI in a rat model of myocardial infarction. Am J Physiol Heart Circ Physiol. 2011; 300: H2238-50.

70. Liu J, Cheng EC, Long RC, Yang SH, Wang L, Cheng PH, et al. Noninvasive monitoring of embryonic stem cells in vivo with MRI transgene reporter. Tissue Eng Part C Methods. 2009; 15: 739-47.

71. Tannous BA, Grimm J, Perry KF, Chen JW, Weissleder R, Breakefield XO. Metabolic biotinylation of cell surface receptors for in vivo imaging. Nat Methods. 2006; 3: 391-6. 
72. Chung J, Kee K, Barral JK, Dash R, Kosuge H, Wang X, et al. In vivo molecular MRI of cell survival and teratoma formation following embryonic stem cell transplantation into the injured murine myocardium. Magn Reson Med. 2011 Nov;66(5):1374-81.

73. Bengtsson NE, Brown G, Scott EW, Walter GA. lacZ as a genetic reporter for real-time MRI. Magn Reson Med. 2010; 63: 745-53.

74. Alfke H, Stoppler H, Nocken F, Heverhagen JT, Kleb B, Czubayko $\mathrm{F}$, et al. In vitro MR imaging of regulated gene expression. Radiology. 2003; 228: 488-92.

75. Gilad AA, McMahon MT, Walczak P, Winnard PT, Jr., Raman $\mathrm{V}$, van Laarhoven $\mathrm{HW}$, et al. Artificial reporter gene providing MRI contrast based on proton exchange. Nat Biotechnol. 2007; 25: 217-9.

76. Chen IY, Greve JM, Gheysens O, Willmann JK, Rodriguez-Porcel $\mathrm{M}, \mathrm{Chu} \mathrm{P}$, et al. Comparison of optical bioluminescence reporter gene and superparamagnetic iron oxide MR contrast agent as cell markers for noninvasive imaging of cardiac cell transplantation. Mol Imaging Biol. 2009; 11: 178-87.

77. Wu JC, Chen IY, Sundaresan G, Min JJ, De A, Qiao JH, et al. Molecular imaging of cardiac cell transplantation in living animals using optical bioluminescence and positron emission tomography. Circulation. 2003; 108: 1302-5.

78. Ardehali R, Inlay MA, Ali SR, Tang C, Drukker M, Weissman IL. Overexpression of BCL2 enhances survival of human embryonic stem cells during stress and obviates the requirement for serum factors. Proc Natl Acad Sci U S A. 2011; 108: 3282-7.

79. Kutschka I, Kofidis T, Chen IY, von Degenfeld G, Zwierzchoniewska M, Hoyt G, et al. Adenoviral human BCL-2 transgene expression attenuates early donor cell death after cardiomyoblast transplantation into ischemic rat hearts. Circulation. 2006; 114: I174-80.

80. Zhang D, Fan GC, Zhou X, Zhao T, Pasha Z, Xu M, et al. Over-expression of CXCR4 on mesenchymal stem cells augments myoangiogenesis in the infarcted myocardium. J Mol Cell Cardiol. 2008; 44: 281-92.

81. Hu S HM, Nguyen PK, Gong Y, Li Z, Jia F, et al. Novel microRNA prosurvival cocktail for improving engraftment and function of cardiac progenitor cell transplantation. Circulation. 2011; epub

82. Francis KR, Wei L. Human embryonic stem cell neural differentiation and enhanced cell survival promoted by hypoxic preconditioning. Cell Death Dis. 2010; 1: e22.

83. Peterson KM, Aly A, Lerman A, Lerman LO, Rodriguez-Porcel M. Improved survival of mesenchymal stromal cell after hypoxia preconditioning: role of oxidative stress. Life Sci. 2011; 88: $65-73$.

84. Ben-David U, Benvenisty N. The tumorigenicity of human embryonic and induced pluripotent stem cells. Nat Rev Cancer. 2011; 11: 268-77.

85. Kooreman NG, Wu JC. Tumorigenicity of pluripotent stem cells: biological insights from molecular imaging. $J R S o c$ Interface. 2010; 7 Suppl 6: S753-63.

86. Lee AS, Tang C, Cao F, Xie X, van der Bogt K, Hwang A, et al. Effects of cell number on teratoma formation by human embryonic stem cells. Cell Cycle. 2009; 8: 2608-12.

87. Horton MA. The alpha v beta 3 integrin "vitronectin receptor". Int J Biochem Cell Biol. 1997; 29: 721-5.

88. Jia F, Wilson KD, Sun N, Gupta DM, Huang M, Li Z, et al. A nonviral minicircle vector for deriving human iPS cells. Nat Methods. 2010; 7: 197-9.

89. Yu J, Hu K, Smuga-Otto K, Tian S, Stewart R, Slukvin II, et al. Human induced pluripotent stem cells free of vector and transgene sequences. Science. 2009; 324: 797-801.

90. Swijnenburg RJ, Schrepfer S, Cao F, Pearl JI, Xie X, Connolly AJ, et al. In vivo imaging of embryonic stem cells reveals patterns of survival and immune rejection following transplantation. Stem Cells Dev. 2008; 17: 1023-9.

91. Robertson NJ, Brook FA, Gardner RL, Cobbold SP, Waldmann H, Fairchild PJ. Embryonic stem cell-derived tissues are immunogenic but their inherent immune privilege promotes the induction of tolerance. Proc Natl Acad Sci U S A. 2007; 104: 20920-5.

92. Swijnenburg RJ, Tanaka M, Vogel H, Baker J, Kofidis T, Gunawan F, et al. Embryonic stem cell immunogenicity increases upon differentiation after transplantation into ischemic myocardium. Circulation. 2005; 112: I166-72.

93. Zhao T, Zhang ZN, Rong Z, Xu Y. Immunogenicity of induced pluripotent stem cells. Nature. 2011; 474: 212-5.

94. Swijnenburg RJ, Schrepfer S, Govaert JA, Cao F, Ransohoff K, Sheikh AY, et al. Immunosuppressive therapy mitigates immunological rejection of human embryonic stem cell xenografts. Proc Natl Acad Sci U S A. 2008; 105: 12991-6.

95. Pearl JI, Lee AS, Leveson-Gower DB, Sun N, Ghosh Z, Lan F, et al. Short-term immunosuppression promotes engraftment of embryonic and induced pluripotent stem cells. Cell Stem Cell. 2011; 8: 309-17. 